\title{
Revenue-sharing Contract of Supply Chain with Sale Effort Cost Partaking
}

\author{
Zhiyong Liu \\ School of Business Administration, South China University of Technology \\ Guangzhou, China \\ E-mail: bmzhyliu@scut.edu.cn
}

\begin{abstract}
As an effective method to coordinate supply chain, revenue-sharing contract cannot function when the demand is uncertain and dependent on the retailer's sale effort. Considering a supply chain with one single supplier serving one retailer, the aforementioned result is explained through the theoretical analysis. To coordinate the supply chain, a new revenue sharing contract with sale effort cost partaking was therefore proposed, and the supply chain coordination can be achieved. The new contract is apt to implement because of few contract parameters. Finally, a numerical example was given to illustrate the model and obtain the optimal allocation proportion of revenue. The proposed model demonstrated that both supplier and retailer can gain more profits when the new contract is applied.
\end{abstract}

Keywords- Supply Chain Coordination; Revenue-sharing Contract; Effort Effect; Cost Partaking

\section{INTRODUCTION}

As an effective method to coordinate supply chain, revenue-sharing contract has been widely applied in practice. It refers to a contract, the supplier offering the retailer a lower wholesale price in return for a percentage of the retailer's sale revenue. Recently some researchers focus on the research field and make much contribution to developing its theory and application. Cachon outlined its strength and weakness in detail[1]. Pana studied its application in video rental industry, and showed that the revenue sharing contract was a useful method to coordinate the video supplier and retailer[2]. Many articles of its application in some other industry can be found. The interested readers can refer to the references [3] and [4].

The aforementioned articles do not consider the situation that the retailer's sales effort can influence consumer's demand. However, it can happen that the retailers always try to attract much more consumers and then improve sale revenue by means of marketing efforts, such as promotion, advertisement and etc. It shows that sale effort should be considered in revenue sharing contract. However, the question arises as to whether the revenue sharing contract with sale effort can coordinate the supply chain. Cachon found that revenue sharing contract could not coordinate supply chain any more when retailer's sale effort affected consumer demand[5]. His research further showed that revenue sharing contract must be adjusted so as to function well. According to the suggestion, some other researchers present the new revenue sharing contract. He Yong developed the revenuesharing contract based on channel rebate and penalty [6]. The retailer can get some channel rebate from supplier if the retailer sells more products than the supplier set before in quantity, otherwise he will pay a penalty. That is to say, the rebate and penalty depend on the sales. The new contract can stipulate the demand and coordinate the supply chain, but cannot work well in practice because of too many contract parameters included. It is essentially a two-part tariffs contract. Xu Zui presented two types of constrained buy-back contract with sales effort effects, which could coordinate the supply chain by constraining the quantity of buying back[7]. Nicola studied the revenuesharing contract combined with Advance Booking Discount policy, in which the consumers could get price discount when advanced booking. The ABD program is intended to entice consumers to pre-commit their orders [8].

Different from the above research, the paper studies the revenue sharing based on sale effort cost partaking, and shows that the contract can coordinate supply chain when the supplier and retailer share the sale effort cost.

\section{QUESTION DESCRIPTION}

Considering a supply chain with one supplier and retailer, in which the supplier supplies the retailer one single product. The supplier and retailer are assumed to be individual rational and risk neutral. According to the demand function dependent on sale effort, the retailer makes a purchasing from the supplier, which in turn supplies the product to meet the retailer's requirements. Assume that the supplier has the unconstrained capacity. The parameters are described as follows:

$\mathcal{W}$ :the wholesale price ;

$p$ :the retail price;

$c$ :the unit manufacturing cost ;

$Q$ :the supply quantity;

$v$ :the salvage value of unsold product;

$e$ :the retailer's sale effort

$g(e)$ $g(0)=0, g^{\prime}(e)>0, g^{\prime \prime}(e)>0$;

$d(e)$ :the impact of sales effort on consumerdemand;

$D(e)$ :the demand function;

$\xi$ :a random variable, with the probability density function $f(\xi)$, and cumulative distribution function $F(\xi)$

$S(Q, e)$ :the expected sale, $S(Q, e)=E \min (Q, D)$

$I(Q, e)$ :the unsold quantity, $I(Q, e)=Q-S(Q, e)$

$\Pi_{T}$ : the expected whole supply chain profit; 
$\Pi_{R}(Q, e)$,:the expected retailer's profit ;

$\Pi_{s}(Q, e)$ : the expected supplier's profit

The retailer sales effort influences demand in two types of fashion, a mul-tiplicative fashion $D(e)=d(e) \xi$ and additive fashion $D(e)=d(e)+\xi$. The paper only considers the first.

According to the newsvendor model, the following expression can be derived: $S(Q, e)=Q-d(e) \int_{0}^{Q / d(e)} F(x) d x$, and $I(Q, e)=d(e) \int_{0}^{Q / d(e)} F(x) d x$

\section{MODEL SETTING}

To achieve supply chain coordination, the supply chain partner's optimal decisions must coincide with maximizing the whole supply chain profit. First considering the expected whole supply chain profit:

\section{A. Whole supply chain profit $\Pi_{T}$}

The whole supply chain profit can be expressed as follows:

$\Pi_{T}(Q, e)=(p-v) S(Q, e)+(v-c) Q-g(e)$.

Supposing $e^{*}$ be the retailer's optimal sale effort, the first order condition is applied and researchers have :

$$
\frac{\partial \Pi_{T}\left(Q, e^{*}\right)}{\partial e}=(p-v) \frac{\partial S\left(Q, e^{*}\right)}{\partial e}-g^{\prime}(e)=0
$$

Similarly, let $Q^{*}$ be the optimal order quantity given the optimal sale effort $e^{*}$, the following equation can hold:

$$
\frac{\partial \Pi_{T}\left(Q^{*}, e\right)}{\partial Q}=(p-v) \frac{\partial S\left(Q^{*}, e\right)}{\partial Q}-(c-v)=0
$$

further, $\frac{\partial S\left(Q^{*}, e\right)}{\partial Q}=1-F(Q / d(e))$, the equation (2) can be solved:

$$
Q=d(e) F^{-1}\left(\frac{p-c}{p-v}\right)
$$

\section{B. Revenue sharing contract without cost sharing}

Under the revenue-sharing contract, the retailer makes a purchase from supplier according to the demand, and the supplier offers the retailer a lower wholesale price (even lower than the unit cost) in return for a propotion of the retailer's sale revenue, supposed to be $\phi$, the retailer and supplier's profit can be expressed as follows:

$$
\begin{aligned}
\Pi_{R}(Q, e, \phi) & =(1-\phi)(p-v) S(Q, e)+[(1-\phi) v-w] Q-g(e) \\
\Pi_{S}(Q, e, \phi) & =w Q-c Q+\phi[p S(Q, e)+v I(Q, e)] \\
& =(w-c+\phi v) Q+\phi(p-v) S(Q, e)
\end{aligned}
$$
(4):

the optimal sale effort can be derived fro $m$ the equation

$$
\frac{\partial \Pi_{R}\left(Q, e^{*}\right)}{\partial e}=(1-\phi)(p-v) \frac{\partial S\left(Q, e^{*}\right)}{\partial e}-g^{\prime}(e)=0
$$

Comparing (1) and (4), coordination can be achieved subject to $\phi=0$. That is to say, revenue sharing contract without cost partaking cannot coordinate the supply chain. The next the paper studies the contract with cost partaking.

\section{Revenue sharing contract with effort cost sharing}

The paper presents the revenue sharing contract with cost sharing, different from traditional model, in which the supplier not only shares sale revenue, but also shares the sale effort cost.

The retailer's expected profit can be expressed as follows:

$$
\Pi_{R}(Q, e, \phi)=(1-\phi)(p-v) S(Q, e)+[(1-\phi) v-w] Q-(1-\phi) g(e)
$$

Correspondingly, the optimal retailer sale effort should satisfy following first order condition.

$$
\frac{\partial \Pi_{R}\left(Q, e^{*}\right)}{\partial e}=(1-\phi)(p-v) \frac{\partial S\left(Q, e^{*}\right)}{\partial e}-(1-\phi) g^{\prime}(e)=0,
$$

Further simplified, researchers have

$$
(p-v) \frac{\partial S\left(Q, e^{*}\right)}{\partial e}-g^{\prime}(e)=0
$$

Similarly, the optimal order quantity should satisfy following condition:

$$
\frac{\partial \Pi_{R}\left(Q^{*}, e\right)}{\partial Q}=(1-\phi)(p-v) \frac{\partial S\left(Q^{*}, e\right)}{\partial Q}-(1-\phi) v-w=0
$$

To achieve coordination, the following conditions must hold:

$$
\left\{\begin{array}{l}
Q=d(e) F^{-1}\left(\frac{p-c}{p-v}\right) \\
(p-v) \frac{\partial S\left(Q, e^{*}\right)}{\partial e}-g^{\prime}(e)=0 \\
w=(1-\phi) c
\end{array}\right.
$$

and $\quad \Pi_{R}(Q, e)=(1-\phi) \Pi_{T}(Q, e)$

$\Pi_{S}(Q, e)=\phi \Pi_{T}(Q, e)$

\section{NUMERICAL EXAMPLE ANALYSIS}

Aiming at a theoretical analysis and comparison, the paper constructs a numerical example based on reference[6]. $d(e)=e, \quad D(e)=e \cdot \xi, \quad g(e)=a e^{2} / 2$, $c=5, \quad v=1, \quad p=15, a=100$. Random variable $\xi$ is uniform distributed over [0,100].

\section{A. Revenue sharing contract with effort cost sharing}

Solving equation (7), researchers have the following solutions:

$$
\begin{aligned}
& e=\frac{25}{7}, \quad Q^{*} \approx 255.1 \quad, \quad S \approx 164, \quad \Pi_{T}^{1} \approx 637.8, \\
& \Pi_{R}^{1}=637.8(1-\phi), \Pi_{S}^{1}=637.8 \phi
\end{aligned}
$$

\section{B. Revenue sharing contract without effort cost sharing}

Based on maximizing the profit of supply chain partner, researchers apply the following first order conditions:

$$
\begin{gathered}
\frac{\partial \Pi_{R}}{\partial Q}=(1-\phi)(p-v) \frac{\partial S(Q, e)}{\partial Q}+(1-\phi) v-w=0, \\
\frac{\partial \Pi_{S}}{\partial Q}=w-c+\varphi v+\varphi(p-v) \frac{\partial S(Q, e)}{\partial Q}=0
\end{gathered}
$$


Comparing $\partial \Pi_{R} / \partial Q$ and $\partial \Pi_{S} / \partial Q$, the relation between wholesale $w$ and unit manufacturing cost $c$ can be derived. $w=(1-\phi) c$. Solving $\partial \Pi_{R} / \partial Q, \partial \Pi_{S} / \partial Q$ and equation (3), the solutions can be derived.

$$
e=\frac{25(1-\phi)}{7}, Q=\frac{12500(1-\phi)}{49} \quad, \quad \Pi_{R}^{2}=637.8(1-\phi)^{2},
$$

$\Pi_{S}^{2}=1275.6(1-\phi) \phi, \Pi_{T}^{2}=637.8\left(1-\phi^{2}\right)$. The solutions with different contract are shown in Table 1 .

TABLE I. SOLUTION WITH DIFFERENT CONTRACT T YPE

\begin{tabular}{cccccc}
\hline Scenario & $\begin{array}{c}\text { Sale } \\
\text { effort }\end{array}$ & $\begin{array}{c}\text { Order } \\
\text { quantity }\end{array}$ & $\begin{array}{c}\text { Supplier's } \\
\text { profit }\end{array}$ & $\begin{array}{c}\text { Retailer's } \\
\text { profit }\end{array}$ & $\begin{array}{c}\text { Whole supply } \\
\text { chain profit }\end{array}$ \\
\hline $\begin{array}{c}\text { With cost } \\
\text { sharing }\end{array}$ & $25 / 7$ & 255.1 & $637.8 \phi$ & $637.8(1-\phi)$ & 637.8 \\
\hline $\begin{array}{c}\text { Without cost } \\
\text { sharing }\end{array}$ & $\frac{25(1-\phi)}{7}$ & $255.1(1-\phi)$ & $1275.6(1-\phi) \phi$ & $637.8(1-\phi)^{2}$ & $637.8\left(1-\phi^{2}\right)$ \\
\hline
\end{tabular}

Based on the above analysis result, it can be concluded that compared with the contract without cost sharing, the new contract can make sure to improve the retailer's sales and profit, and what's more, improve the whole supply chain profit. It shows that the activity of cost sharing gives the retailer an incentive to try its best to increase sales, and thus discuss the supply chain partner's profit.

\section{Analysis of supply chain profit}

The supplier and retailer's profit is depicted as the following Fig. 1. The profit curve of contract without cost sharing is shown in dash line.

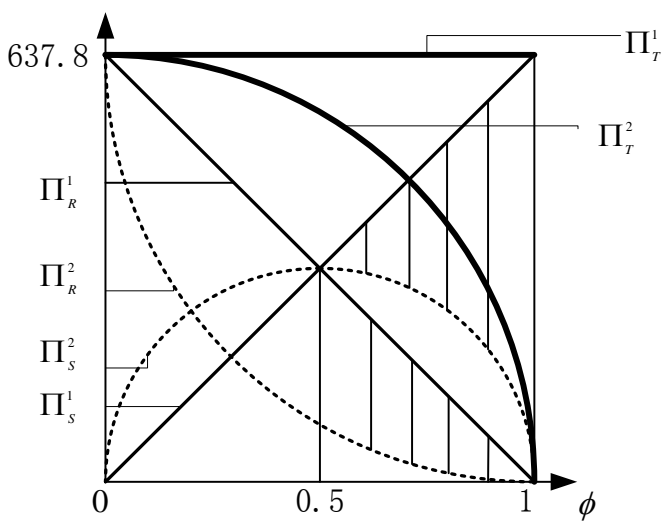

Figure 1. Profit curve

Fig. 1 shows that the change of $\phi$ can impact the profit. When supplier and retailer shares the effort cost, the supplier's profit increases as $\phi$ increases, whereas the retailer's profit decreases as $\phi$ increases. The whole supply chain profit keeps constant, and equal to 637.8. In contrast to the contract model with cost sharing, the supplier's profit increases as $\phi$ increases from 0 to 0.5 , whereas decreases as $\phi$ increases from 0.5 to 1 when the supplier do not share the sale effort cost. The supplier's profit reaches its maximum as $\phi$ equal to 0.5 . The whole channel profit decreases as $\phi$ increases.

In respect to whole supply chain channel, the costsharing contract is preferred. As for supplier and retailer, the Pareto principle should be achieved. That is the partner's profit under the condition of cost sharing should not be lower than the counterpart condition.

$$
\left\{\begin{array}{l}
\Pi_{R}^{1} \geq \Pi_{R}^{2} \\
\Pi_{S}^{1} \geq \Pi_{S}^{2}
\end{array}\right. \text { (Incentive Compatibility) }
$$

Therefore, $\phi \geq 50 \%$. At present, the supplier's profit increases whereas the retailer's profit decreases. If it decreases to an extent that the revenue equal to 0 , the retailer will decline to accept the contract. In order to make sure the contract is accepted, the retailer's reserved profit should be clear. Now researchers study the retailer's profit when no contract is implemented.

The retailer's profit:

$$
\Pi_{R}=p\left(Q-\frac{Q^{2}}{200 e}\right)+v \frac{Q^{2}}{200 e}-w Q-\frac{a e^{2}}{2}
$$

The supplier's profit: $\Pi_{s}=(w-c) Q$

According to first order condition, the solutions can be derived:

$$
w=7.5, e=2, Q \approx 107.6, S(Q, e) \approx 78.8, \Pi_{S} \approx 269
$$

, $\Pi_{R} \approx 201.8$

Considering above incentive compatibility condition, the following inequality should hold:

$$
\left\{\begin{array}{l}
\Pi_{R}^{1} \geq 201.8 \\
\Pi_{S}^{1} \geq 269 \\
\phi \geq 1 / 2
\end{array}\right.
$$

Solving it, $50 \% \leq \phi \leq 68.3 \%, \Pi_{S} \in[318.9 ; 436]$, $\Pi_{R} \in$ [201.8;318.9], $\Pi_{T}=637.8$

When the proportion of the supplier's revenue $\phi$ range from $50 \%$ to $68.3 \%$, the revenue sharing contract with cost partaking can be accepted by both, and the supply chain coordination can be achieved.

\section{CONCLUSIONS}

When the sale effort affects the demand, the traditional revenue-sharing contract cannot coordinate the supply chain any more. However, if the sale effort cost is partaken by both, the coordination can be achieved. The new contract is in accordance with the philosophy of 'mutual risk and mutual profits'. Additionally, it should be noticed that the cost partaking contract is implemented with the condition that the sale effort cost must be verified by the supplier. Otherwise, the retailer maybe exaggerates purposely the sale cost. Therefore, the revenue-sharing contract with asymmetric information of sales effort cost needs to be further investigated. 


\section{REFERENCES}

[1] Cachon G. Lariviere M. Supply chain coordination with revenuesharing contracts: strengths and limitations[J]. Management Science, 2005, 51(1):30-44

[2] Dana J, Spier K. Revenue sharing and vertical control in the video rental industry [J]. The journal of Industrial Economics, 2001,49(3): 223-245

[3] Giannoccaro I, Pontrandolfo P. Supply chain coordination by revenue sharing contracts $[\mathrm{J}]$. International Journal of Production Economics, 2004,89(2):131-139

[4] Chauhan S S, Proth J M. Analysis of a supply chain partnership with revenue sharing $[\mathrm{J}]$. International Journal of Production Economics, 2005,97(1):44-51

[5] Cachon G P. Supply chain coordination with contracts[M]. Amsterdam, Holland: Elsevier Science Publishers, 2004,227-339
[6] He yong, Yang Deli, Wu qinglie. Revenue-sharing contract of supply chain with effort dependent demand[J]. CIMS, 2006, 12 (11) : 1865-1868

[7] Xu zui, Zhu daoli, Zhu wengui. Supply chain coordination under buy-back contract with sales effort effects[J]. SYSTEMS ENGINEERING - THEORY \& PRACTICE, 2008, 4 : 1 11

[8] Nicola Bellantuono, Ilaria Giannoccaro,etc. The implications of joint adoption of revenue sharing and advance booking discount programs [J]. International Journal of Production Economics, 2009, 121:383 394

[9] Ilaria Giannoccaro, PierpaoloPontrandolfo. Negotiation of the revenue sharing contract: An agent-based systems approach[J]. International Journal of Production Economics, 2009 , 122: 558 566

[10] $\mathrm{Hu}$ benyong, Lei dong, Chen xu. Supply Chain Option Sale-surety Contract Based on Revenue Sharing and Effort Cost partaking[J]. Journal of industrial engineering and engineering management, 2010, 24 (3) 